\title{
Development of Aluminum Foams by Different Methods and Evaluation of its Density by Archimedes Principle
}

\author{
B.U. Vinay and K.V. Sreenivas Rao
}

\begin{abstract}
Methods for producing metal foams are many, but obtaining repeatability in the properties is very difficult. The main challenge posed by the metal foam is that obtaining homogeneous porosity. Although lot of problems involved in the development of metal foams, research people are attracted to the metal foams because of its attractive properties like acoustic damping, bomb mitigation, light weight etc. By considering the development of Aluminum foams as important aspect, some methods have been adopted and attempts have been made to produce metal foams at lower cost. The methods developed for the Aluminum foams were Aluminum foam production using $\mathrm{NaCl}$ crystal as a place holder in the Al melt, Aluminum foam production using $\mathrm{NaCl}$ crystal as a place holder in sand salt mold, Aluminum foam production using $\mathrm{NaCl}$ crystal as a place holder by simultaneous pouring concept.The problems associated in each process and its effect on the density and porosity of the foam were discussed.
\end{abstract} Holder

Keywords--- Al Foams, Density, NaCl, Porosity, Space

\section{Abbreviations}

$\begin{array}{ll}\text { Al : } & \text { Aluminum } \\ \text { DP : } & \text { Die pouring } \\ \text { MGI : } & \text { Melt Gas Injection } \\ \text { SSM : } & \text { Salt Sand Mold } \\ \text { SP : } & \text { Simultaneous Pouring } \\ \mathrm{NaCl}: & \text { Sodium Chloride } \\ \mathrm{MJ}: & \text { Measuring Jar }\end{array}$

\section{INTRODUCTION}

$\mathrm{M}$ ETAL foam is a cellular structure and it contains porosity [1]. The porosity in the metal is actually a defect, but in case of metal foam it is intentionally created and it should be homogeneous throughout the material [2]. Metal foams offer a wide range of industrial applications. But main challenge faced is to produce metal foam itself.

B.U. Vinay, Asst. Professor, Department of Mechanical Engineering, Sahyadri College of Engineering, Mangalore, India, E-mail: vinay1988@gmail.com

K.V. Sreenivas Rao, Professor, Department of Mechanical Engineering, Siddaganga Institute of Technology, Tumkur, India.

DOI: 10.9756/BIJIEMS.1866
This is because obtaining the repeatability in the properties of metal foams is still not possible, controlling the process parameters in the method is of high risk, cost involved in the process [3]-[5]. Other main problem involved here is that designers not getting the results accurately and they are getting the insufficient data [3].

Some applications of metals foams are as vibration absorber in machine member, bomb mitigation element in military services, metal filters for industries, support for catalytic reactors etc [1],[6].

Especially $\mathrm{Al}$ foams found a wide range of applications in industries, military sectors etc, since the Al itself has the lot of potential applications in many areas of research and industry. Actually foaming process in a metal is to create gas liquid mixture that is bubble creation in the melt. But foaming process is different for different metals and processes [7]-[8].

Metal foam production techniques can be generally classified as Liquid route and powder route. Various parameters are involved in the process are responsible for the quality, size and shape of the metal foam to be produced. The parameters involved are different from process to process. Controlling these process parameters is difficult and thus understanding the process concept is difficult, particularly in liquid route controlling process parameters is a big task. Hence the methods developed for the production of metal foams are still in incipient stage [6]-[15]. Some of the process parameters which play pivotal role in metal foam production are:

i. Matrix material

ii. Melt temperature

iii. Type of foaming agent

iv. Decomposition Temperature of Foaming agents

v. Particle size of the Foaming agent

vi. Foam stabilizers

vii. Density of Foam Stabilizers: Particle size

viii. Selection of process

In this work attempt has been made to develop the foams via different techniques and compared their density property and $\%$ porosity. The reasons for the considering the density property is that, the main objective of every material research person is that to reduce the density of the material and to increase the strength. In this work attempt has been made to reduce the density of the $\mathrm{Al}$ foam via three different techniques. They are DP, SSM, SP. In future, we will focus on obtaining the metal foam with good strength to weight ratio by using different methods. Although there is lot of methods 
available for the production $\mathrm{Al}$ foams, the attempt has been made in this work to develop the metal foam at lower cost using the easily available materials like $\mathrm{NaCl}$ etc. lot of work is needed in this regard and there great scope for research in this area. Figure 1 shows the common methods which are available for the production of $\mathrm{Al}$ metal foams.

COMMON METHODS FOLLOWED TO PRODUCE METAL FOAMS

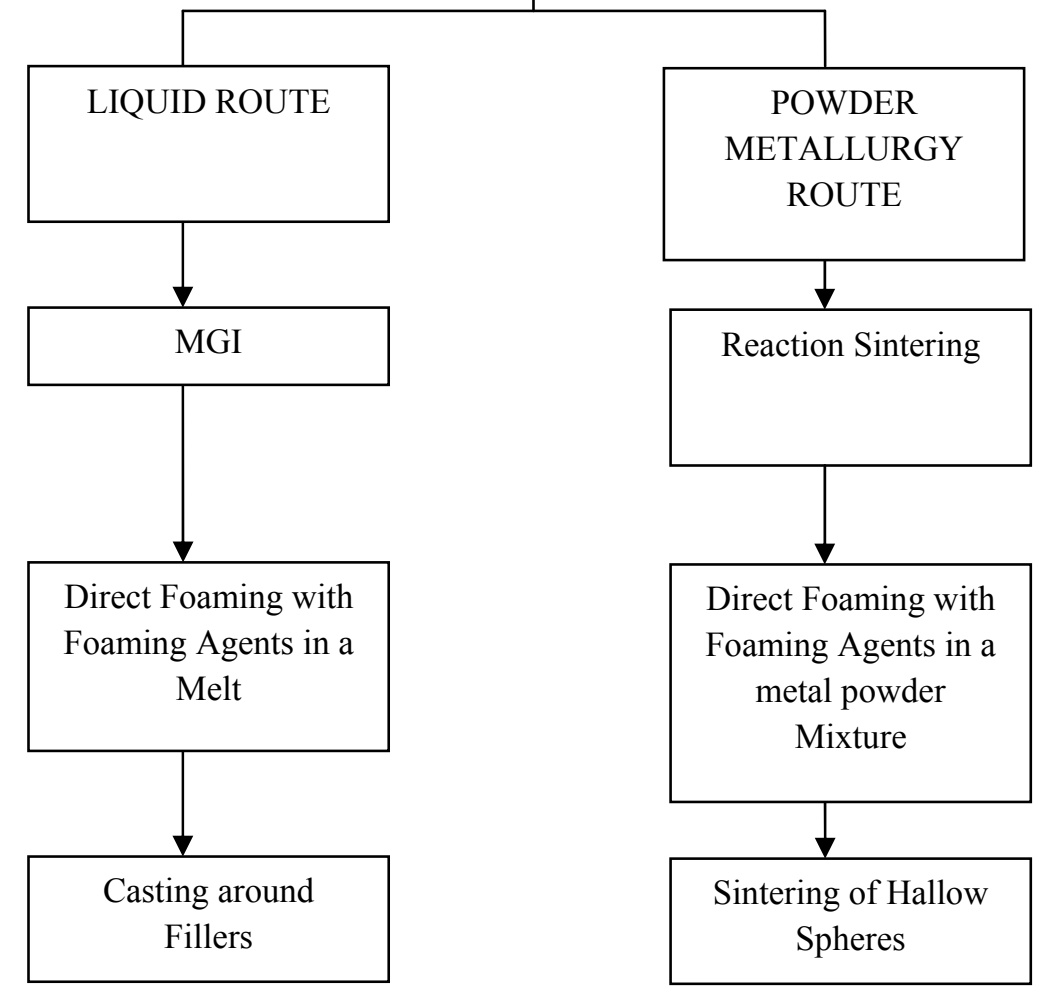

Figure 1: Common Methods Followed for the Producing Al Metal Foams 


\section{EXPERIMENTAL PROCEDURE}

\subsection{Aluminum Foam Production using $\mathrm{NaCl}$ Crystal as a Space Holder in the Al Melt (DP Method)}

By keeping the density differences of $\mathrm{NaCl}(2.165 \mathrm{~g} / \mathrm{cc})$ and $\mathrm{Al}(2.7 \mathrm{~g} / \mathrm{cc})$ in mind the $\mathrm{NaCl}$ crystals were place in a mold of required shape and size. The Al melted was poured into the mould and allowed for solidification. Before the experiment it was assumed that when pouring due to density difference, $\mathrm{NaCl}$ crystals floats and $\mathrm{Al}$ melt will takes place the place inside the salt. But the Al rapidly solidifies. After removing the cast part from the mold leaching was done in hot water. From observation only bottom part of the components gets foam structure and in depth it is not achieved. The mold prepared for the experiment is shown in figure 2 and foam structure obtained was shown in figure 3 .

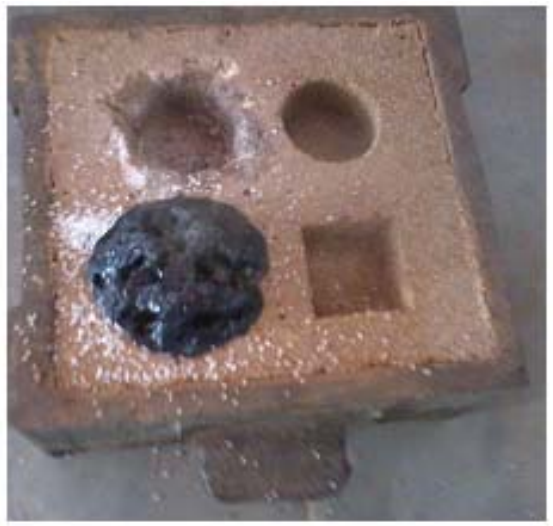

Figure 2: Open Mold used for Casting Al Foam

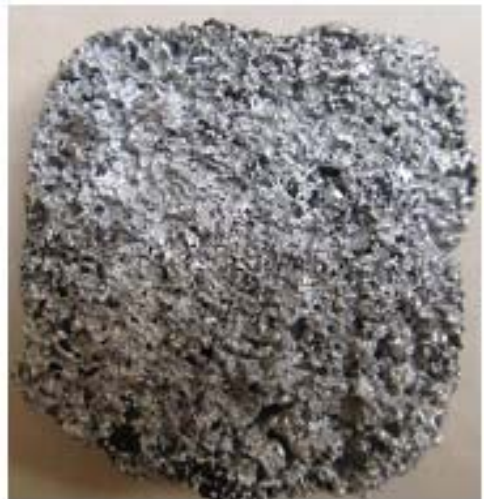

Figure 3: Macrograph of Foam Obtained

\subsection{Al Foam Production using $\mathrm{NaCl}$ Crystal as a Space Holder in Sand Salt Mold (SSM Method)}

Attempt in this experiment has been made to achieve the uniform porosity in the metal. The prepared mold was preheated in an electric oven and it kept in oven until the $\mathrm{Al}$ gets melted. The step followed to produce the melt is same as in earlier case. Then Melt was poured into the preheated mold cavity and adding the salt into the melt followed by gentle stirring. Mold is allowed for air cooling and solidified part is taken out and leached in hot water for 10 to 20 minutes. Finally almost cylindrical Al foam obtained. Mold prepared for this method is shown in figure 4. Foam structures obtained by this method are shown in figure 5 .

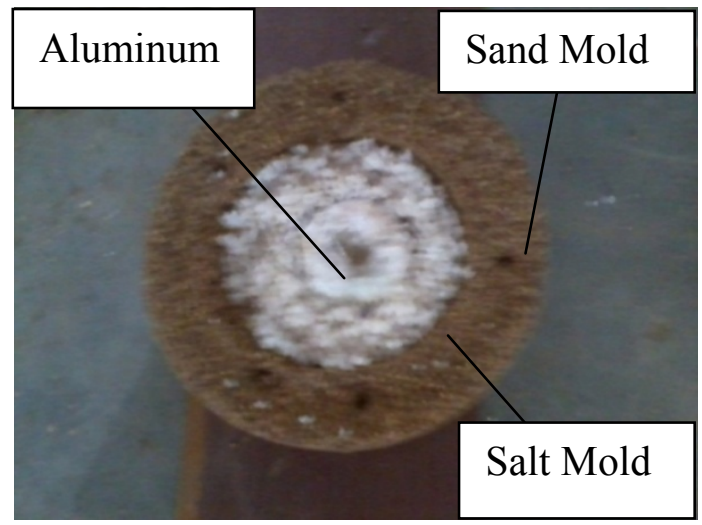

Figure 4: Sand + Salt Mold after Pouring
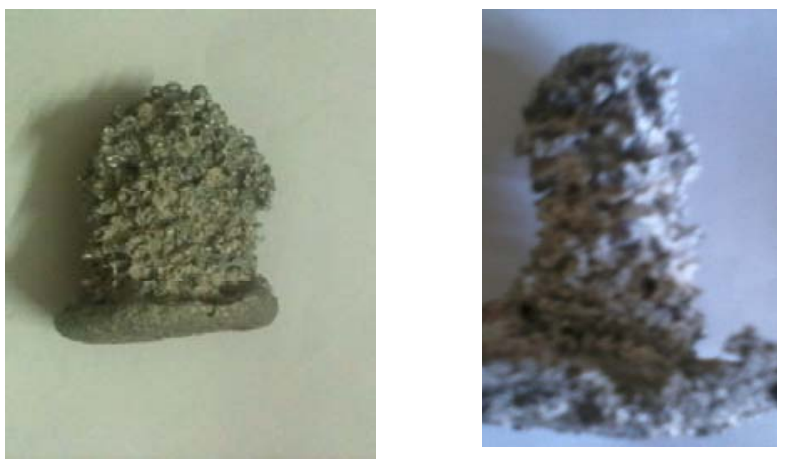

Figure 5: Foam Structure Created by Sand + Salt Mold

\subsection{Al Foam Production using $\mathrm{NaCl}$ Crystal as a Space Holder by Simultaneous Pouring Concept (SP Method)}

Although above experiments were little bit help in getting the uniform porosity the drawback is that unable to achieve porosity inside the material is a problem. Hence an attempt made to pour the molten metal and salt simultaneously in the required mold cavity. The mold prepared for this is shown in figure 6 . The mold was prepared in such a way that melt was poured in a runner and simultaneously salt into the riser gate. The assumption was made before doing the experiment is, there will be uniform mixing takes in the melt due to simultaneous pouring. But the problem arises by the coagulation of salt crystals as the pouring takes place. But the foam structure obtained was better than the foam obtained in the previous experiments, which shown in figure 7 . 


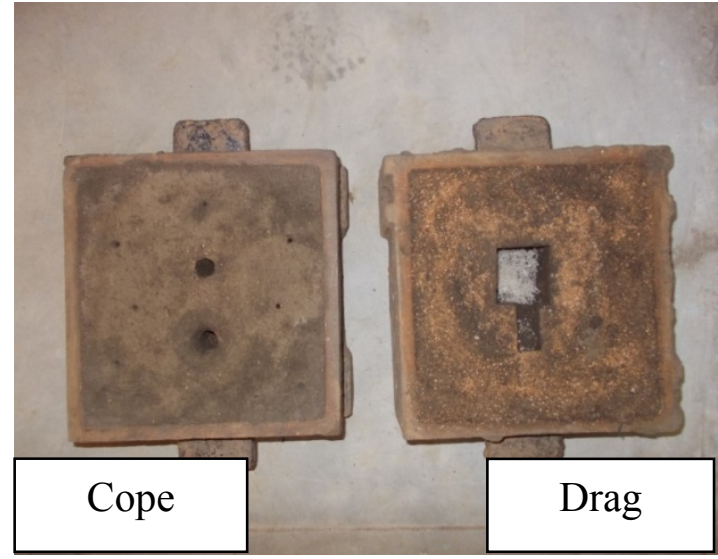

Figure 6: Mold Prepared for Simultaneous Pouring of Salt Crystals and Al Melt

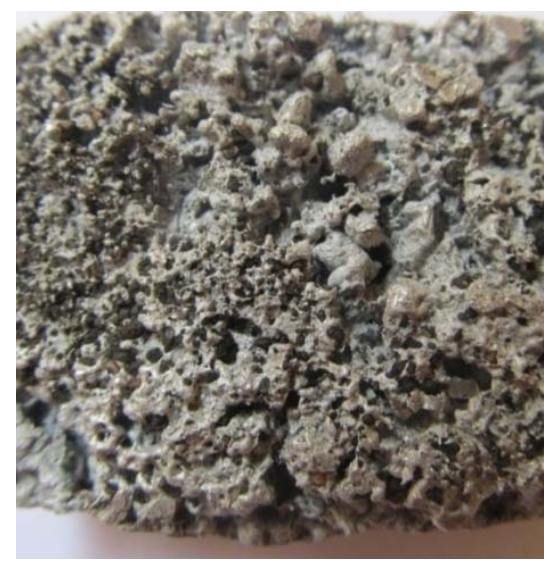

Figure 7: Foam Obtained by Simultaneous Pouring of $\mathrm{NaCl}$ Crystals and Molten $\mathrm{Al}$

\section{RESULTS AND DISCUSSION}

\subsection{Evaluation of Density of the Al Foam}

Foams obtained are in irregular shape and density calculation by normal method is not possible. However it can be calculated by using Archimedes principle.

Measuring Jar (MJ) as shown in figure 8 was used to calculate the density of the Al foam obtained by different routes. Density of the foam was calculated as follows

\section{To find the actual volume of the Foam specimen}

1. Water was filled in a MJ for specified amount. E.g. $500 \mathrm{ml}$. it is the initial water level in the MJ.

2. Then immerse the foam specimen into the water contained MJ slowly and new level of water is recorded.

3. Difference between the initial and final level of water in the MJ, which gives the actual volume ( $\mathrm{V}$ in $\mathrm{cc}$ ) of the foam specimen.

4. Weigh the foam specimen and its mass ( $m$ in grams) is recorded.

5. Now the density of foam $\left(\rho_{\mathrm{f}}\right)$ is calculated as follows.

$$
\rho_{\mathrm{f}}=\frac{m}{V} \mathrm{~g} / \mathrm{cc}
$$

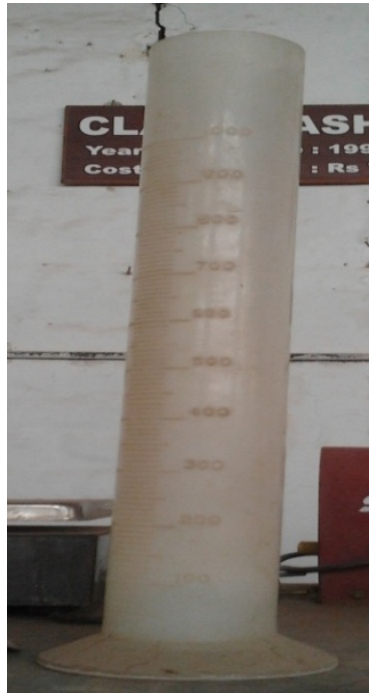

Figure 8: Measuring Jar used for Volume Calculation

\subsection{Evaluation of the \%Porosity of the Al foam}

Porosity also plays the very important role as the density in deciding the foam quality. As the density of the foam decreases, the porosity also increases. But the increase in porosity not helps instead for the foam uniform porosity is the important parameter. In the cast parts actually porosity is a problem, but in the metal foam synthesis main objective is to develop uniform porosity. Simple concept of the evaluating the $\%$ porosity is given below.

$$
\% \text { of Porosity }=\frac{\rho \mathrm{Al}-\rho \mathrm{f}}{\rho \mathrm{Al}} \times 100
$$

Where $\rho_{\mathrm{Al}}=$ Density of the aluminum, $\rho_{\mathrm{f}}=$ Density of the foam.

The density and \%porosity of the foam obtained is tabulated in the table 3.1.

\subsection{Comparison between the Different processes in terms of Density}

Table 1: Shows that ability of the different methods, how the density of the foam is reduced. By observing table it can be said that method like space holder technique using $\mathrm{NaCl}$ helps in reducing the density up to the extent. But density is not only the parameter to decide the property of the foam and some other parameters like porosity, compactness etc also play vital role. But the methods for characterizing the above properties are still incipient stage. Therefore much more efforts are required to develop and characterize foam. By our experiment we got the irregular shapes of $\mathrm{Al}$ metal foams, but it is very difficult to calculate the density of irregular solid, therefore we adopted the Archimedes principle to calculate the density of obtained foams. In the table 1 the density and \% porosity of foams obtained by different methods are shown. By seeing the data it can be stated that Density of $\mathrm{Al}$ foam increases with increase in \%porosity. Therefore attempt has been made to develop the $\mathrm{Al}$ foam with uniform porosity and achieved little success. 


\begin{tabular}{|c|c|c|c|c|c|c|c|c|}
\hline \multirow{2}{*}{$\begin{array}{l}\text { Sl. } \\
\text { No. }\end{array}$} & \multirow[t]{2}{*}{ Method Followed } & \multirow{2}{*}{$\begin{array}{c}\text { Initial } \\
\text { Volume of } \\
\text { Water in } \\
\text { pipe, cc }\end{array}$} & \multirow{2}{*}{$\begin{array}{c}\text { Final } \\
\text { Volume of } \\
\text { Water in } \\
\text { pipe, cc }\end{array}$} & \multirow{2}{*}{$\begin{array}{c}\text { Actual } \\
\text { volume of } \\
\text { Specimen V, } \\
\text { cc }\end{array}$} & \multirow{2}{*}{$\begin{array}{l}\text { Mass } \\
\mathrm{m}, \mathrm{g}\end{array}$} & \multicolumn{2}{|c|}{ Density $\rho=\mathrm{m} / \mathrm{v}, \mathrm{g} / \mathrm{cc}$} & \multirow{2}{*}{$\begin{array}{l}\text { \% of porosity, } \\
\frac{\rho A l-\rho f}{\rho A l} \times 100\end{array}$} \\
\hline & & & & & & $\begin{array}{l}\text { Density of } \\
\text { the foam } \\
\text { obtained, } \rho_{\mathrm{f}}\end{array}$ & $\begin{array}{l}\text { Density of the } \\
\text { Aluminum, } \rho_{\mathrm{Al}}\end{array}$ & \\
\hline 1 & DP & 500 & 520 & 20 & 47.8 & 2.39 & 2.7 & 11.48 \\
\hline 2 & SSM & 500 & 520 & 20 & 40 & 2.0 & 2.7 & 25.92 \\
\hline 3 & SSM & 500 & 530 & 30 & 58.30 & 1.94 & 2.7 & 28.14 \\
\hline 4 & SP & 500 & 510 & 10 & 23.40 & 2.34 & 2.7 & 13.33 \\
\hline
\end{tabular}

\section{CONCLUSION}

The method for producing the Al foam was developed by pouring the molten $\mathrm{Al}$ into the heated mold containing $\mathrm{NaCl}$ crystals. In this method foam was obtained, but the structure was not satisfactory. Aluminum metal foams were synthesized by Space Holder $(\mathrm{NaCl})$ technique. Though this method help in the formation of metal foam the quality of the foams produced was not satisfactory. The production of the $\mathrm{Al}$ foam from the simultaneous pouring concept found to be better than the other methods. But the main problem is that fluidity of Aluminum is low and while pouring in the mold it rapidly solidifies, which results in coagulation of salt particles inside the mold and obtained foam structure still not satisfactory. In terms of density the foam structure obtained by simultaneous pouring concept was good, but density is not only the parameter which decides the quality of the foam or any material. Therefore much more efforts are needed in development of Aluminum foams and its characterization methods.

\section{SCOPE FOR FUTURE WORK}

By utilizing the materials like $\mathrm{NaCl}$, Sand we have made a attempt to obtain the $\mathrm{Al}$ foam with good foam structure. As the metal foam producing is challenging process, there is lot of scope in this area and in future using the experience from past experiments, utilizing the available resources effectively we can develop the $\mathrm{Al}$ metal foam with higher quality. Further the $\mathrm{NaCl}$ can be used as the space holder in the powder metallurgy route and foam can be produced.

\section{REFERENCES}

[1] John Banhart, "Manufacture, characterisation and application of cellular metals and metal foams", Progress in Materials Science 46, Pp.559-632, 2001.

[2] V. GERGELY, H.P. DEGISCHER, T.W. CLYNE, Recycling of MMCs and Production of Metallic Foams, Vol.3, (ISBN: 0-080437214); Pp. 797-820,

[3] Rossella Surace and Luigi A.C. De Filippis, Investigation and Comparison of Aluminium Foams Manufactured by Different Techniques, Advanced Knowledge Application in Practice.
[4] LI Da-wu. Et al. Preparation and characterization of aluminum foams with $\mathrm{ZrH}_{2}$ as foaming agent, Trans. Nonferrous Met Soc. China 21, Pp. 346-352, 2011.

[5] Takashi Nakamura, Development of a new foaming agent, Material Transactions, Vol.43, No.5. Pp.1191-1196, 2002.

[6] M.F. Ashby, A.G. Evans, N.A. Fleck, L.J. Gibson, J.W. Hutchinson and H.N.G. Wadley, "Metal Foams: A Design Guide", ButterworthHeinemann publications.

[7] Dennis Weaire, "Foam Physics", Advanced Engineering Materials, Vol. 4, Pp.10, 2002

[8] Tetsuji Miyoshi, Masao Itoh, Shigeru Akiyama, and Akira Kitahara, "ALPORAS Aluminum Foam: Production Process, Properties, and Applications", Advanced Engineering Materials, 2, No. 4, 2000.

[9] Y.Y. Zhao and D.X. Sun, "A Novel Sintering-Dissolution Process for Manufacturing Al Foams", Scripta mater. 44, Pp.105-110, 2001.

[10] N. Michailidis, F. Stergioudi, "Establishment of process parameters for producing Al-foam by dissolution and powder sintering method", Materials and Design 32,Pp. 1559-1564, 2011.

[11] M.F. Ashby, A.G. Evans, N.A. Fleck, L.J. Gibson, J.W. Hutchinson and H.N.G. Wadley, "Metal Foams: A Design Guide", ButterworthHeinemann publications.

[12] R. Surace, L.A.C. De Filippis, E. Niini, A.D. Ludovico, and J. Orkas, "Morphological Investigation of Foamed Aluminum Parts Produced by Melt Gas Injection", Hindawi Publishing Corporation, Advances in Materials Science and Engineering, Vol. 2009, Article ID 506024, 9 pages.

[13] V.C. Srivastava, K.L. Sahoo, "Processing, stabilization and applications of metallic foams. Art of science", Materials Science-Poland, Vol. 25, No. 3, 2007.

[14] Jan Schroers, Chris Veazey, Marios D. Demetriou, and William L. Johnson, "Synthesis method for amorphous metallic foam", Journal of Applied Physics Vol. 96, No.12.

[15] Varužan Kevorkijan, "Low Cost Aluminium Foams Made $\mathrm{By}^{\mathrm{CaCO}_{3}}$ Particulates", Association of Metallurgical Engineers of Serbia, MJoM Vol. 16 (3), Pp. 205-219, 2010.

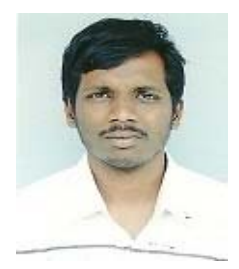

B.U. Vinay, Assistant Professor, Dept. of Mechanical Engineering , Sahyadri College of Engineering, Mangalore. E-mail: vinay1988@gmail.com 